\title{
Study on Power Supply Service Satisfaction Evaluation Based on Fornell Model
}

\author{
Lei Ye ${ }^{1}$, Hongbo $\mathrm{Wu}^{1}$, Hanbing Yue ${ }^{1}$, Tiantian Sun ${ }^{1}$, Wei $\mathrm{Li}^{1}$ and Furong $\mathrm{Liu}^{2}$ \\ ${ }^{1}$ Customer Service Center of State Grid Henan electric power company, Zhengzhou, China \\ ${ }^{2}$ Henan Epri Electric Power Technology co., Ltd, Zhengzhou, China
}

\begin{abstract}
To improve customer Satisfaction, Henan branch of China State Grid build power supply service Satisfaction evaluation system to analysis service quality based on data from 95598 telephone hotline and questionnaire survey considering the psychological need of customers. Only by this could standardize the services and integrated the enterprise image.
\end{abstract}

Keywords-fornell model; 95598 work order; service quality evaluation

\section{INTRODUCTION}

Electric power is the important guarantee of social and economic development, the power supply service quality had a great influence on social production and living, so power companies must constantly improve the level of power supply. To evaluate the quality of service, enterprises can analysis the result of customer satisfaction. The higher customer satisfaction is, the better the quality of service is. In the past, some scholars used Customer Satisfaction Rate for tool of customer satisfaction degree evaluation, but it is unable to specific analysis of the influencing factors of customer satisfaction and influence degree through the questionnaire survey assessment, software analysis and comparing the level of the power supply service (JiaZhenwang,2004).Based on organizational behavior in the psychological contract theory to design the lateral scale, Zhou Cuicui (2011) studied relationship between psychological contract and customer satisfaction of the State Grid and thought that psychological contract affect customer satisfaction more deeply than trade psychological contract. Some scholars draw lessons from international experience, customer satisfaction index (CSI) is used to comprehensive evaluation, using econometric methods to grasp the impact of various factors which will help to find the corresponding promotion strategy. One of the widely-used customer satisfaction measurement models is Fornell model.

By analyzing the power 95598 satisfied and unsatisfied work order and six variables in Fomell model, Wang Haomiao (2015) put forward to improve product strategy to improve customer satisfaction in the power supply service activities. Through the analysis of the current electric power industry, such as marketing present situation and existing problems, Shi Xuyang (2016)put forward the strategy of the power supply company marketing which are on the one hand, power supply companies should improve their management level, on the other hand, should pay attention to the introduction of professional marketing talent and training.

\section{FORNELL MODEL}

In 1989, Fornell put forward a logic model which also is a econometrics model including the customer expectations, perception and other factors as shown in Figure 1. At present, Fornell model has become the world's most widely used customer satisfaction measurement model. The model mainly studies the various factors that affect customer satisfaction, and customer satisfaction and the relationship between these factors. The model is composed of six variables: customer expectation, Customer Perceived Quality, customer perception of value, customer satisfaction, customer loyalty, customer complaints.

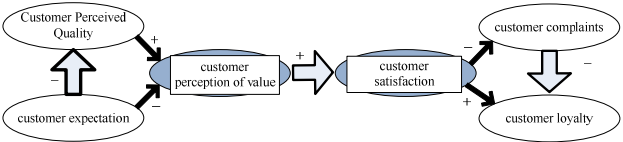

FIGURE I. FORNELL MODEL

Among them, customer expectations, customer perception of quality and customer perception of value is the premise variables, three of the model the relationship between them determine the customer satisfaction, customer complaints and customer loyalty the three variables. (a) customer expectations: customer expectations of service in its demand for services, to understand customer expectations is the premise of enterprise and improve customer satisfaction.(b) the customer perception of quality, customer service quality in the process of service for the actual feeling and perception, the perception is the core element of the customers are satisfied with the service.(c) the customer perception of value: in the process of service, customers to pay the costs and profits experience, its core is to compare the price and quality of service. (d) customer satisfaction: by comparing the three premises in front of the variable, it is concluded that customer satisfaction. Perception after the event than expected in advance, the customer will feel satisfied.(e) the customer complaint: Perception after the event is lower than the prior expectations, the customer can produce complain, enterprises should pay more attention to customer complaints and complaints, to improve and improve the service quality of enterprises.(f) customer loyalty, customer will repeat purchase or enthusiasm to others recommend this enterprise, these customers will bring stability to the development of enterprises, cultivate customer loyalty is the enterprise long-term goals for customer satisfaction assessment project. 
In the model, the arrow next to the line of positive and negative, said the interrelation between the variables and the related degree."+", "-" means positive and negative correlation. There are a variety of correlations between these variables in the model. For example, customer expectation and customer perception of value are negative correlation relationship between "customer satisfactions". The high expectations, and its actual "perception" will reduce accordingly; the higher the expectation, the more difficult to improve customer satisfaction and satisfaction levels drop. And a negative correlation relationship between customer satisfaction and customer complaints, but was positively related to customer loyalty in and relationship. The customer satisfaction is lower, the higher the customer satisfaction and customer loyalty.

\section{POWER Supply Service Quality Evaluation SYSTEM}

According to the power supply company customer utilization classification standard, the investigation is divided into resident and unit users. The residents could be divided into urban and rural users according to gender and age. And the unit users are divided into three types such as industry, commerce and agriculture industry. In June 2016, our power supply service quality survey was made with 1300 samples for residents in Henan province and 200 samples of unit users. All information was gathered from 95598 customer service hotlines, repair work order, and questionnaire survey. The power supply service quality evaluation index system is constructed as shown in Figure 2.

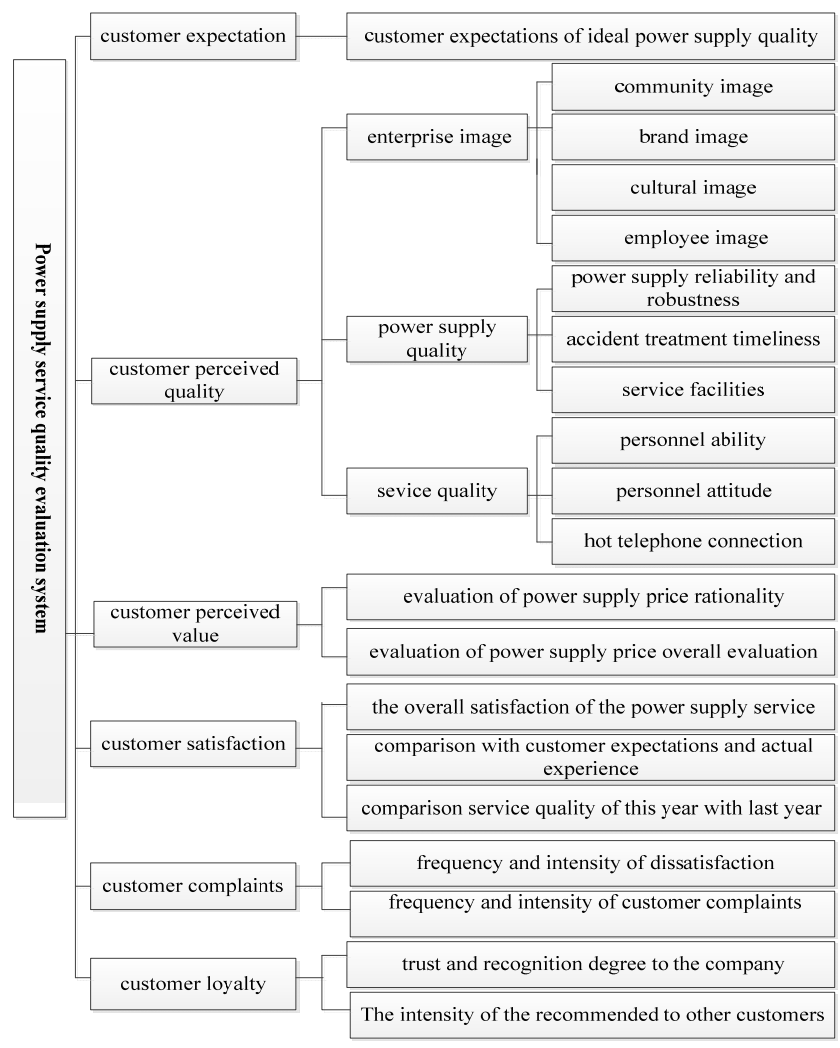

FIGURE II. POWER SUPPLY SERVICE QUALITY EVALUATION SYSTEM BASE ON FORNELL MODEL

According to Fornell model, customer service quality evaluation of the enterprise depends on the six aspects of mutual comparison: customer expectation, customer perceived quality, customer perceived value, customer satisfaction, customer loyalty, customer complaints. In order to make the evaluation more closely to the construction of the service quality, the specific evaluation index is detailed as four secondary indexes which are customer perceived quality, customer perceived value, customer satisfaction, customer loyalty. Three and four level indicators are segmented according to the related project in power supply service quality questionnaire.

According to the experience of the market research data and expert scoring, the weights are secondary to: customer perceived quality (0.3645), customer perceived value (0.2637), customer satisfaction (0.2143), customer loyalty (0.1575), see table 1. On the final 18 evaluation factors, in order to guarantee the accuracy of the evaluation with the seven Likert scale, the grade evaluation can be divided into seven levels: best (100 points), good (85.7), better (71.4), medium (57.1), ordinary (42.9), worse (28.6), and worst (14.3).

\section{THE RELIABILITY ANALYSIS}

Cronbach's alpha coefficient is used to make reliability analysis in order to check every factor whether has the similar features which are often between 0 and 1.If the coefficient is less than 0.6 , it is generally believed that the reliability is insufficient. It is more reliable between 0.7 and 0.8 , quite reliability between 0.8 and 0.9 . is obtained from the following formula. 


\section{The Power Supply Service Quality ANalysis}

\section{A. Customer Perceived Quality Analysis}

The four index of customer perception of the quality contains 11 evaluation factors which adopts the following two formulas to calculate: $A$ is the results of customers perceive evaluation, the independent variable ivaries from 1 to 3 which respectively stands for corporate image, quality of power supply and service quality. The independent variable $\mathrm{j}$ varies from 1 to 11 which respectively stand for 11 indexes such as community image, brand image and cultural image, etc. denotes the corresponding points. And is the ratio of number of customers of the sample proportion to the total number of customers.

TABLE I. POWER SUPPLY SERVICE QUALITY EVALUATION SYSTEM INDEXES

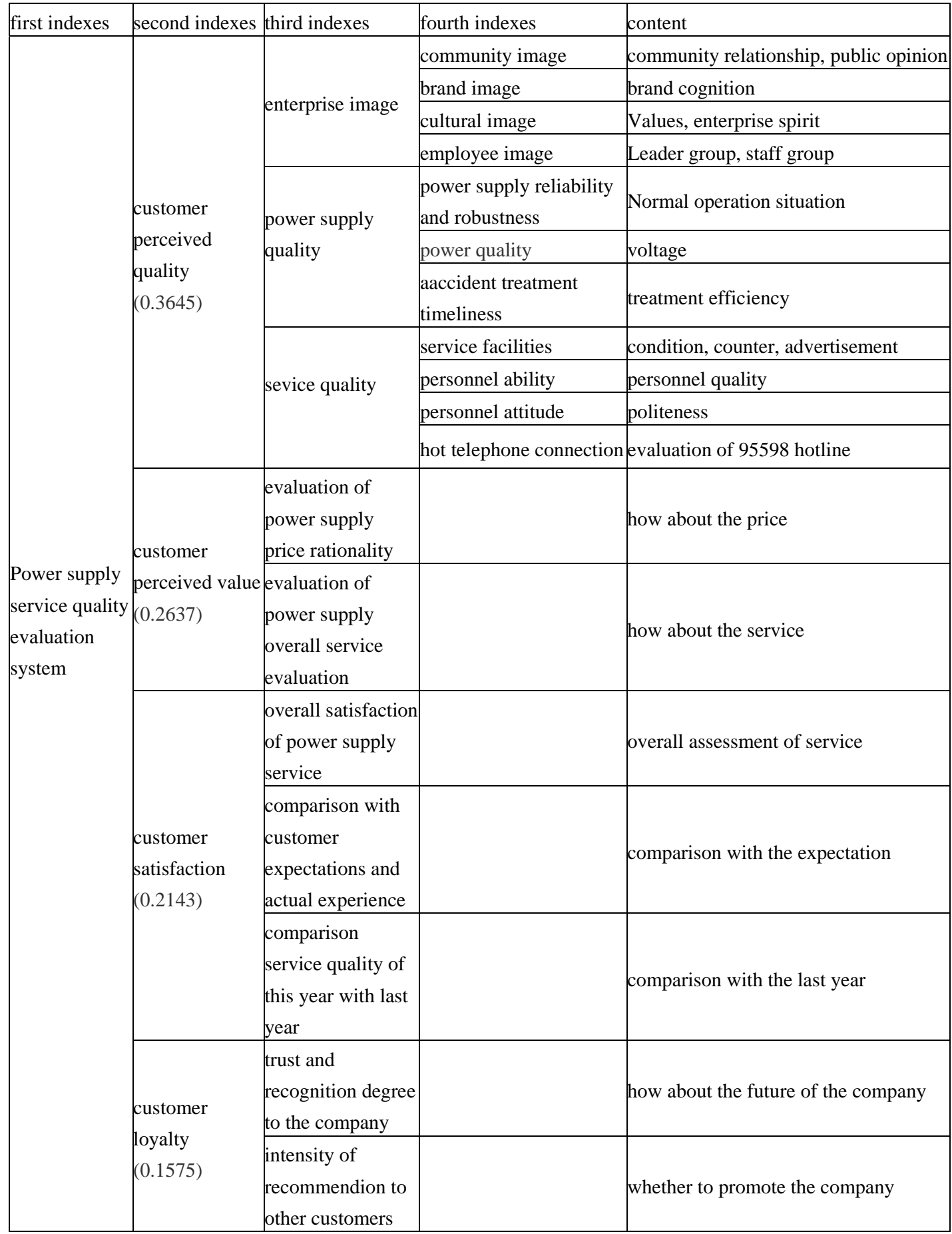




\section{B. Customer Perceived Value Analysis}

Customer perception of value contains two evaluation factor, calculated using the following formula: $\mathrm{B}$ is the results of customer perceived value, the independent variable $\mathrm{i}$ varies from 1 to 2 which respectively according to the customer for evaluation on the rationality of power supply price and the customer to the service level of power supply. The results show that the customer perceived value is 79.5. And the customers of electricity price rationality score is 80.2 points, and the service level of power supply score is 78.7 points.

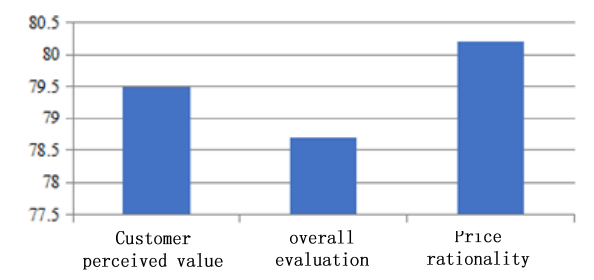

FIGURE III. CUSTOMER PERCEIVED VALUE ANALYSISC.

\section{Customer Satisfaction Analysis}

Customer satisfaction mainly inspects three evaluation factors, calculated using the following formula: $\mathrm{C}$ stands for the quality of power supply service and customer satisfaction, and the independent variables I varies from 1 to 3 respectively for the overall satisfaction of the power supply service customers compared with the expectation of customer satisfaction. The results show that customer satisfaction is 83.2, among them, the customer satisfaction is 85.3, compared with 81.1 score of the expectation of customer satisfaction.

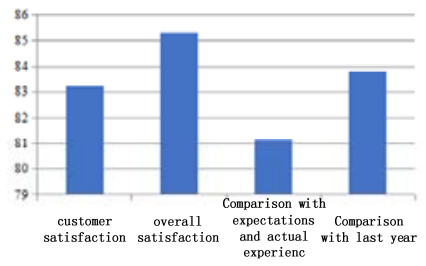

FIGURE IV. CUSTOMER SATISFACTION

\section{Customer Loyalty Analysis}

Customer loyalty mainly reviews the two evaluation factors, calculated using the following formula: D stands for customer loyalty to power supply company, and the independent variable i values from 1 to 2 which respectively means the customer's confidence in the power supply company development prospects and customers recommend the power supply. The results show that the customer loyalty score is 85.8. Among them, the customers have confidence in the development prospects of power supply with score of 90.7 points. But for power supply service recommendation intention is still weak, the score is only 80.9 points. Due to the uniqueness of power resources and power supply, power supply market has not yet formed an effective competition, so customers in the use of the special products and services don't spend more time to choose products and directly have to receive the power supply of the company's products and services.

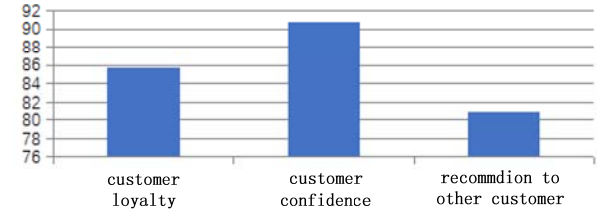

FIGURE V. CUSTOMER LOYAKTY

\section{E. Power Supply Service Quality Analysis}

Customer power supply service quality comprehensive evaluation for power supply is calculated by the following formula: $\mathrm{S}$ stands for the customer the comprehensive evaluation of the power supply service quality including four indicators: customer perceived quality, customer perceived value, customer satisfaction, customer loyalty with a, b, c, d respectively for four indicators in the evaluation system of weights. The results show that the comprehensive evaluation quality of power Supply Company is 82.1 points which the four component scores are 81.7 points, 81.7 points, 83.2 points and 85.8 points.

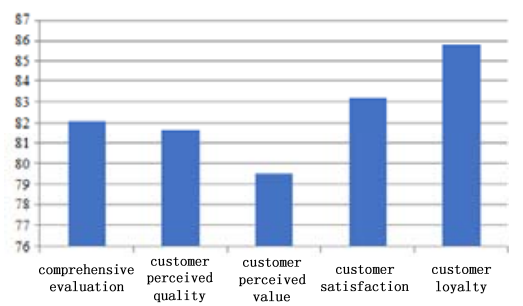

FIGURE VI. CUSTOMER OVERALLEVALUATION ON SERVICE QUALITY

In general, the quality of power supply company service customer evaluation is good which is higher than last year's score. The customer has the strong sense of reliability to power supply quality although there still has a gap to the expiration. Thankfully this gap is narrowing. As the model shows, when customer expectations are below actual the perception of service, customer satisfaction is low.

\section{CONCLUSION}

Through the above analysis of power supply service quality, we can find that: a. The quality of power supply needs to improve According to the customers on the quality of power supply, the evaluation has improved over the last year, but the power supply reliability and accident treatment timely evaluation are not so high.

\section{A. Need to Increase Service Consciousness}

The results show that the personnel of the power supply company business hall service are low efficiency and lack of service with a smile. Residential users reflect that 95598 customer service personnel are not very skilled and service attitude is poor. So the company should strengthen management and training of employees which includes improving the service consciousness of the personnel and the service attitude. 
B. Meter Reading, Billing and Standards Need to be Clarified

The survey shows users are not very familiar with meter reading and billing standard. Meter reading personnel sometimes copy wrongly especially for rural users. The company should strengthen the propaganda and get more information via APP. And it is also important to study and implement the rules and regulations strictly. According to customer investigation, to clarify non-standard fees according to regulations and to standardize management of the rural power supply copy are essential. Furtherly the company should enhance rush fee collectors attitude and sense of responsibility to avoid errors and ensure the electric power customer rights and interests. Especially, the company must simplify the business transaction process, shorten time and improve efficiency.

\section{The Ttreatment Failure Should be Timely.}

The survey found in summer the frequent power outages would seriously affect the customer's life. Fault repair personnel left the scene, and failure phenomenon still exists. Emergency workers have poor service attitude. The breakdown maintenance time is too long beyond customer psychological endurance.

\section{ACKNOWLEDGMENT}

Fund Project NO. 521702150013, Science project of Henan branch of China State Grid.

\section{REFERENCES}

[1] JIA Zhen-wang. The Discussion of Test Program of Power Supply Enterprise Customer Satisfactory Index. Power Demand Side Management.2014(6)

[2] ZHANG Hua-li, Li Qing-yan, LIU Hui.A Case Study of Xi'an Inbound Tourist Satisfaction Based on ACSI. Shaanxi Xueqian Normal University Journal,2014(8).

[3] Henan branch of State Grid. The power supply service customer satisfaction survey. China electric power press.2010(3).K. Elissa, "Title of paper if known," unpublished. 